\title{
Misconceptions about the Hubble recession law
}

\section{Wilfred H. Sorrell}

Published online: 21 July 2009

(C) Springer Science+Business Media B.V. 2009

Erratum to: Astrophys Space Sci (2009) 323: 205-211

DOI 10.1007/s10509-009-0057-z

Under the heading: 4 The expanding universe hypothesis, four lines before the conclusion, the line

The best-fit match to the data requires graphite dust needles with radii $a=0.03 \mu \mathrm{m}-0.07 \mu \mathrm{m}$ and a uniform mass density $\rho_{\text {dust }}\left(t_{0}\right)=3 \times 10^{-24} \mathrm{gm} \mathrm{cm}^{-3}$.

should read:

The best-fit match to the data requires graphite dust needles with radii $a=0.03 \mu \mathrm{m}-0.07 \mu \mathrm{m}$ and a uniform mass density $\rho_{\text {dust }}\left(t_{0}\right)=3 \times 10^{-34} \mathrm{gm} \mathrm{cm}^{-3}$.

The online version of the original article can be found under doi:10.1007/s10509-009-0057-z.

W.H. Sorrell $(\bowtie)$

Department of Physics and Astronomy, University of Missouri-St. Louis, St. Louis, Missouri 63121, USA

e-mail: sorrellw@umsl.edu 